\title{
Editorial \\ Psicología cultural: una perspectiva sistémica contemporánea
}

\author{
Mónica Roncancio Moreno, Ignacio Brescó de Luna, Angela Branco, Elsa Mattos
}

El denominador común de los trece artículos que integran el presente monográfico podría describirse por su interés en estudiar cómo los individuos actúan y se desenvuelven en determinados contextos socioculturales. Estos contextos son concebidos como algo más que el mero entorno físico o geográfico, como sistemas de significado que constriñen y, a su vez, posibilitan las formas que tenemos de interpretar el mundo (incluyendo a nosotros mismos) y de actuar en él. En eso consiste básicamente la psicología cultural: en asumir que vivimos en un mundo no solo físico, sino sobre todo simbólico cargado de significado, con un conjunto de herramientas heredadas culturalmente, desde artefactos, como el Smartphone, hasta normas sociales, pasando por discursos, imágenes, símbolos, rituales, himnos, monumentos, refranes e historias; herramientas que, en definitiva, guían nuestra acción, pero que, al mismo tiempo, hacemos nuestras, dotándolas así de un sentido propio y personal.

Sin embargo, más allá de la consideración del contexto, en tanto conjunto de herramientas culturalmente disponibles, cabría preguntarse, siguiendo a Rosa (2000), ¿qué añade a la Psicología el adjetivo cultural? Para responder a esta pregunta podríamos partir de un enfoque relati- vamente extendido en la disciplina consistente en comparar a individuos de distintos países o grupos mediante sus resultados en cuestionarios y pruebas estandarizadas, por ejemplo, sobre percepción. Mediante este tipo de estudios se sostiene, por ejemplo, que la percepción de los individuos pertenecientes a culturas individualistas (tradicionalmente equiparadas a lo que se conoce como 'cultura occidental') tienden a enfocarse analíticamente en los objetos y sus atributos, mientras que los individuos de culturas colectivistas (tradicionalmente localizadas en países asiáticos u 'orientales') tienden a enfocarse de manera holística en las relaciones entre tales objetos (Nisbett, 2003).

Estos estudios han sido inicialmente útiles para demostrar que los resultados obtenidos en el llamado 'mundo occidental' no pueden extrapolarse, sin más, a otros lugares (Henrich, Heine \& Norenzayan, 2010). Sin embargo, estos estudios también acarrean algunos problemas. Así, mediante generalizaciones (como 'cultura occidental', 'cultura europea' o 'cultura española'), estos estudios tienden a operar con una noción de cultura como algo homogéneo, relativamente fijo, consistente y estable en el tiempo; una noción de cultura que Valsiner (2014) equipara con la

Universidad Pontificia Bolivariana. Correo electrónico: monica.roncancio@upb.edu.co

** Aalborg University.

**** Universidade de Brasilia.

**** Universidade Católica do Salvador. 
metáfora del contenedor, por entenderse como un espacio delimitado que albergaría a individuos con características psicológicas supuestamente similares. Desde un punto de vista metodológico, este enfoque implica concebir la cultura como un marco (o variable independiente) mediante el que comparar diferentes procesos psicológicos, entendidos como variables dependientes, como sería la percepción.

Como señala Rosa (2000), propiamente hablando, no podría hablarse de una psicología cultural, pues el adjetivo cultural poco añadiría al sustantivo psicología, en la medida en que la cultura quedaría relegada al rol de variable o circunstancia ambiental que operaría externamente sobre lo psicológico, sin acabar de explicarse la relación entre ambos elementos. En último término, podríamos decir que esta noción de cultura se emplearía como un falso elemento causal en explicaciones tautológicas del tipo: los occidentales son individualistas debido a la cultura occidental.

Ni qué decir tiene que la metáfora del contenedor resulta problemática en tiempos de globalización, donde ideas, personas y prácticas sociales circulan por el mundo adaptándose y contribuyendo a la transformación de distintos entornos locales. Tomando esto en cuenta, ¿deberíamos considerar a estas personas o prácticas como parte de la cultura del grupo receptor o como cuerpos extraños dentro de ella? Como puede intuirse, en último término, esta visión resulta potencialmente peligrosa al naturalizar categorías culturales, entendidas como bloques homogéneos, en términos de nosotros y ellos (véase Reicher \& Hopkins, 2001); algo en modo alguno ajeno a determinados discursos políticos actuales, cada vez más presentes en nuestras sociedades.

Este sería, de forma un tanto esquemática, el planteamiento general - así como una de sus principales críticas - de lo que se conoce como psicología transcultural (o cross-cultural psychology, en inglés), una corriente que, como señala Rosa
(2000), intenta traer la psicología a la cultura, comparando distintos procesos psicológicos ubicados dentro de distintos marcos culturales. Por el contrario, el objetivo principal de la psicología cultural sería el de traer la cultura a la psicología, estudiando cómo los individuos se apropian y hacen uso de distintos artefactos culturalmente disponibles, transformando con ello el entorno y también a sí mismos. En el primer caso, la cultura se entendería en forma de contenedor, mientras que, en el segundo, se entiende como una herramienta. Una herramienta que, como tal, deja de ser algo externo que opera sobre el individuo. De hecho, la propia noción de herramienta implica la noción de un individuo activo que hace uso de ella con base a fines y contextos de actuación concretos y cambiantes. En otras palabras, desde esta perspectiva teórica, ningún entorno cultural existe independientemente del modo en que los humanos nos apropiamos y hacemos uso de él. Aquí, cultura y psicología dejan de estudiarse como variables independientes y dependientes, respectivamente, sino que se entienden como elementos constitutivos uno del otro.

Así, como señala Vygotsky (1978), el uso y continua renovación de las herramientas culturales ha permitido a los humanos rebasar los límites del desarrollo puramente biológico, impuesto por la naturaleza y expandir así nuestras funciones psicológicas. Por ejemplo, la expansión en la capacidad de memoria puede explicarse (desde un punto de vista socio-genético) por la mediación de distintos artefactos culturales incorporados en la actividad humana a lo largo de la historia. Mediación implica la transformación de una relación mediante la intervención de un tercer factor, como puede ser recordar por medio de un álbum familiar, de una nota escrita, o de un monumento (véase Brescó \& Wagoner, 2019). Por decirlo más claramente, los humanos manipulamos de forma activa nuestra relación con el entorno por medio de distintas herramientas y con ello modificamos nuestras capacidades psicológicas, como, por 
ejemplo, nuestra memoria (véase Wagoner, 2018). En palabras de Vygotsky (1978), la esencia de la civilización residiría, precisamente, en el hecho de que construimos deliberadamente memoriales para no olvidar.

Como puede verse, el adjetivo cultural modifica aquí el término psicología de un modo no anecdótico o tangencial, en la medida en que nos hace dirigir la mirada, no hacia generalizaciones obtenidas de distintos grupos - entendidos como entidades culturales estancas-, sino hacia individuos concretos usando herramientas culturales en contextos específicos. La psicología cultural nos hace reparar, en definitiva, no en una noción de cultura fosilizada, sino en una noción de cultura en acción. Esto añade, a su vez, elementos importantes a la hora de entender los fenómenos psicológicos, no en términos de causalidad mecánica (del tipo, la cultura $\mathrm{X}$ causa personas o conductas Y), sino considerando un mundo cambiante en el que las personas (con distintas herramientas a su alcance) actúan dando sentido al mundo y a sus propias acciones en función de sus experiencias pasadas y de sus respectivas metas de futuro. Este último aspecto añade, tal como señala Rosa (2000), aún otro elemento más a considerar, como sería el del tiempo y la historia; un tiempo cuyo transcurso hace emerger no solo nuevas realidades materiales (por ejemplo, distintos tipos de memoriales), sino nuevos significados y formas de interpretarlos; formas susceptibles de acabar alterando el propio mundo material (modificando, destruyendo o creando nuevos memoriales) $\mathrm{y}$, con ello, las condiciones en las que tendrán lugar otras acciones en el futuro (otras formas posibles de recordar o conmemorar el pasado).

Por último, pero no menos importante, hay otro sentido en el que el adjetivo cultural afecta a la psicología, como es la consideración del rol de los procesos afectivo-semióticos y el uso metodológico de la reflexividad para una comprensión más adecuada del fenómeno humano. Y es que, como nos recuerda Rosa (2000), la psicología misma es un producto cultural y, como tal, suministra herramientas que median e inciden en el modo en el que interpretamos el mundo y también a nosotros mismos.

El objetivo del presente número especial es acercar la psicología cultural al contexto de la psicología latinoamericana (véase Brescó, Roncancio, Branco \& Mattos, 2019). El número arranca con el artículo de Martin Packer titulado "Psicología cultural: introducción y visión general", en el cual el autor presenta algunos antecedentes de la psicología cultural, así como sus principales conceptos y discusiones metodológicas para su abordaje. El artículo siguiente, "Ateliê de pintura com idosos acolhidos: desenvolvimento, subjetividade e arte em diálogo", de Tatiana Yokoy y Daiane Souza Guedes, explora la transformación de la identidad de adultos mayores en centros de acogida en Brasil desde una perspectiva de la psicología cultural del desarrollo mediante el arte. Posteriormente, Angela Branco y Milena Oliveira, en el artículo "Dialogical self-development in obese women: A cultural psychology longitudinal study", analizan la trayectoria de desarrollo del self de tres mujeres obesas durante un período de dos años, en el cual fueron sometidas a cirugía bariátrica para perder peso. Por su parte, María Fernanda González, en su artículo "Narrativas de mujeres activistas: participación y transformación entre lo personal y lo político", estudia la narrativa de 12 mujeres activistas por los derechos sexuales y reproductivos de Entre Ríos, Argentina. En el quinto artículo de este número, "Trajetórias em transição: a produção de significados de uma migrante venezuelana”, Rômulo Ataides França y Silviane Bonaccorsi Barbato analizan la producción de significados sobre sí misma de una migrante venezolana en Brasil.

Los dos artículos siguientes discuten las relaciones de los sujetos con medidas de privación de libertad en el Brasil. Así, en el artículo "Violência e privação de liberdade: um estudo sobre trajetórias juvenis a partir do Radar de 
Relações Interpessoais”, María Claudia Santos Lopes de Oliveira y Kelita Rejanne Machado realizan un estudio ideográfico longitudinal que tuvo como objetivo el análisis de las trayectorias de vida de tres jóvenes durante el cumplimiento de una medida socioeducativa de privación de libertad. Por su parte, Sirlene Lopes de Miranda y Danilo Silva Guimarães, en su artículo "Relações interpessoais e trocas dialógicas na execução penal de metodologia alternativa", discuten los conflictos dialógicos vivenciados por hombres privados de libertad en el sistema penitenciario de Brasil, centrándose en aquellos casos donde una misma persona asume una doble posición: el cumplimiento de su condena, por un lado, junto con la participación en la administración de la institución penal, en tanto responsable de la seguridad, por el otro.

En el artículo "Resistance to rupture in the self-facing a school failure experience: case study of an adolescent", Ramon Cerqueira Gomes, María Virgínia Machado Dazzani y Giuseppina Marsico discuten los significados creados por un adolescente a partir del fracaso escolar y la transformación de los posicionamientos sobre sí en este proceso. En la línea de los estudios con adolescentes, Elsa Mattos en el artículo "Desenvolvimento do self e os processos imaginativos na transição para a adolescencia: um estudo de caso" presenta las reconfiguraciones del sí mismo de un adolescente en transición a partir del uso de recursos imaginativos.

Posteriormente, dos artículos presentan investigaciones con niños. "Racial Intimidation at a School in Amazonas, Colombia: Elevating the Voices of Children through Iconic Narration", de Carmen Cristina Martínez Torres, Lilian Patricia Rodríguez Burgos y Leidy Evelyn Díaz Posada, discute la dinámica de la intimidación racial desde la perspectiva de 20 niños indígenas de una escuela urbana en Leticia, en el Amazonas colombiano. Por su parte, Mónica Roncancio Moreno y Danna Aristizabal Oviedo, en su artículo "Modalidades de interacción y valores sociales emergentes en niños" presentan la dinámica de interacción en relación con los valores sociales de cooperación, competición, individualismo y solidaridad que emergen en parejas de niños de colegios públicos colombianos.

En otra línea, Irina Rasskin-Gutman e Ignacio Brescó de Luna en su artículo "Identidad y alteridad en libros de texto escolares: un estudio de caso sobre la representación de Al-Andalus", analizan las formas de producción de alteridad - entendida como la otra cara de la identidadarticuladas en la representación de Al-Andalus en un libro de texto de Ciencias Sociales utilizado en un centro de enseñanza secundaria de la Comunidad de Madrid, España. En el último artículo, "El aprendizaje-servicio como aporte a la formación profesional: un análisis de caso a partir de la metodología quinta dimensión", José Eduardo Sánchez Reyes y Yamileth Bolaños Martínez describen el proceso de participación de estudiantes universitarios de psicología en la adaptación e implementación de un modelo educativo denominado proyecto Mohán. El modelo se asume como experiencia de aprendizaje-servicio y se explora cómo esta metodología contribuye a la comprensión del oficio del psicólogo.

En suma, nuestra meta con este número especial es ofrecer a los lectores de Avances en Psicología Latinoamericana una contribución sustancial en términos de clarificar las bases teóricas y epistemológicas de la psicología cultural, como también proveer ejemplos de cómo llevar a cabo estudios empíricos de acuerdo con el marco general este abordaje. Creemos que presentar a los psicólogos e investigadores una psicología abierta a la condición sociocultural del individuo puede ser una contribución relevante para fomentar análisis y debates novedosos en nuestro campo. 


\section{Referencias}

Brescó, I., Roncancio, M., Branco, A., \& Mattos E. (2019). Cultural Psychology: A Two-Way Path between Mind and Culture/Psicología cultural: un camino de ida y vuelta entre la mente y la cultura. Studies in Psychology/Estudios de Psicología, 40(1), 1-9. Doi: 10.1080/021093 95.2019.1565388

Brescó, I., \& Wagoner, B. (2019). The psychology of modern memorials: the affective intertwining of personal and collective memories. Estudios de Psicología, 40(1), 219- 244. Doi: 10.1080 /02109395.2018.1560024

Henrich, J., Heine, S. J., \& Norenzayan, A. (2010). The weirdest people in the world? Behavioral and Brain Sciences, 33, 61-135.
Nisbett, R. E. (2003). The geography of thought. Nueva York, NY: Free Press.

Reicher, S., \& Hopkins, N. (2001). Psychology and the end of history: A critique and a proposal for the psychology of social categorization. Political Psychology, 22(2), 387-407.

Rosa, A. (2000). ¿Qué añade a la Psicología el adjetivo cultural? Anuario de Psicología, 31(4), 27-57.

Valsiner, J. (2014). An invitation to cultural psychology. Londres: Sage.

Vygotsky, L. S. (1978). Mind in society: The development of higher psychological processes. Cambridge, MA: Harvard University Press.

Wagoner, B. (ed.) (2018). Handbook of Culture and Memory. Nueva York, NY: Oxford University Press. 